August 12019

\title{
Why a Constant Number of Vertebrae? - Digital Control of Segmental Identity During Vertebrate Development
}

The somite cycle controls a digital, chromatin-based counter that defines segmental identity and body plans in vertebrate animals.

\author{
Andrzej Kudlicki \\ University of Texas Medical Branch \\ andy@kudlicki.net askudlic@utmb.edu
}

\begin{abstract}
It is not understood how the numbers and identities of vertebrae are controlled during mammalian development. The remarkable robustness and conservation of segmental numbers may suggest a digital nature of the underlying process.

Here I propose a mechanism that allows cells to obtain and store the segmental information in digital form, and to produce a pattern of chromatin accessibility that in turn regulates Hox gene expression specific to the metameric segment.

The model requires that a regulatory element be present such that the number of occurrences of the motif between two consecutive Hox genes equals the number of segments under the control of the anterior gene. This is true for the recently discovered HRC3 motif, associated with histone modifications and developmental genes. The finding not only allows correctly predicting the numbers of segments using only sequence information, but also resolves the 40-year-old enigma of the function of temporal and spatial collinearity of Hox genes.
\end{abstract}

The logic of the mechanism is illustrated in an animated video: https://youtu.be/4a3XOQ7Lz28. I also discuss how different aspects of the proposed mechanism can be tested experimentally. 
Keywords: Hox genes; collinearity; segmental identity; chromatin modifications; vertebral malformations; vertebrae; Hox synteny; somitogenesis; Notch pathway

\section{Introduction}

\subsection{Numbers in metazoan body plans}

Across the animal kingdom, strong conservation of numerical aspects of the body plan is observed [2]. The numbers of digits, teeth, segments, or even the total number of cells are often invariant within species. In vertebrates, including humans, the numbers of metameric segments in each region of the spine (cervical, thoracic, lumbar, sacral, coccygeal), as well as the total number of vertebrae are highly conserved not only within a species, but often for larger phyla [3]; for example almost all mammalian species have exactly seven cervical vertebrae [4], turtles have eight cervical and ten thoracic vertebrae, etc. It is however not understood how these numbers are encoded in the genome, or what mechanism is responsible for reliably generating the correct numbers of vertebrae and their respective identities. Such mechanism of counting segments would have to be very robust. In humans the only relatively common variation is the L5 sacralization, otherwise the numbers of segments within each region are altered (usually on one side) only in certain rare cases of congenital vertebral malformations, for example in hemivertebrae or cervical ribs. Studies in model animals show that the total number of somites (segment precursors) is not affected by reducing the size [5-7] or axial length [8] of the embryo, nor by environmental factors, cell size or ploidy, nor by interventions such as notochord ablation [9]. While the prevailing view in the field is that the numerical aspects of segmental identity are determined by the cells sensing a gradient in concentration of a morphogen or precise, segment-specific timing of expression [10], there is no satisfactory explanation of how the cells could perform an absolute measurement of morphogen concentration or of time with a high precision, required for determining their location along the anteroposterior axis. Likewise, it has been proposed that the total number of somites is controlled by a finely-tuned ratio between the somite cycle and the total duration of somitogenesis until the presomitic mesoderm is exhausted [11], however later experiments contradict this explanation [9] and no explanation is offered for the high precision and reproducibility of the process.

\subsection{Regulation of segmental identity}

Segmental identity in mammals and other bilaterians is mediated by Hox genes. Hox genes encode a group of transcription factors, responsible for developmental processes and establishment of the body plan [12-15]. Hox genes also exhibit a remarkable collinearity: conserved arrangement on chromosomes that is the same as their order of activation along the body axis. The regulation is very precise, for example, the regions of activity of Hox genes are tightly confined to specific rhombomeres [16-18] or to segments 
of the vertebrate anteroposterior body axis [19]. The vertebrate Hox genes are synchronized: the spatiotemporal expression domains of paralogs from the $A, B, C$ and $D$ clusters are generally identical along the A-P axis [20-22], with only minor differences between the clusters (for example in members of the Hox4 group of paralogs).

Despite 40 years of active research, the mechanisms of Hox gene regulation have remained elusive. Evolutionary conservation suggests that the coupling between collinearity in the chromosomal scale and collinearity along the body axis is significant, but neither its function nor the underlying mechanism have been explained [23-25]. Hox genes tend to be inhibited by more posterior ones, but this process (termed "posterior prevalence") appears not to be universal, and is likely secondary to an unknown primordial mechanism of regulation [26, 27]. More importantly, posterior prevalence can only account for the posterior boundary of the expression domain of Hox genes. The anterior boundaries appear to be functionally more relevant for patterning the vertebral column, but the mechanism of establishment of the anterior boundaries of Hox expression domains has remained unknown. Recent evidence suggests that chromatin structure $[28,29]$ and histone demethylation, especially removal of the H3K27me3 histone mark, play important roles in activation of Hox genes [30-33], also numerous enhancers have been identified, especially for the posterior Hox genes [34-38]. Nonetheless, the mechanism precisely directing chromatin modifications to specific loci at the right time and place has remained mysterious [36]. It has been argued that the ancestral patterning strategy is based on progressive opening of chromatin in the Hox clusters in the $3^{\prime}$ to $5^{\prime}$ direction [30, 39], possibly mediated by a timer mechanism [24]. It is however not known how the speed of this progression would be controlled, and how the mechanism would be initiated or terminated in segment-specific manner. Also the enhancer landscape evolves fast within Hox clusters $[40,41]$ and is unlikely to be at the base of a primordial process that is responsible for Hox gene collinearity and is shared by divergent groups of bilaterian animals. Despite significant effort, neither the CTCF binding site nor long non-coding RNAs has been confirmed to play a primary role in regulation of chromatin in the Hox clusters [37, 42].

Recently, we have discovered the HRC3 signature, a conserved regulatory element associated with most Hox genes and with other developmental transcription factors [43]. The element is approximately $180 \mathrm{bp}$ long and is defined by a pattern in the DNA structure rather than its sequence. Specifically, the signature is defined by a significantly high peak of periodogram [44-47] of the hydroxyl radical cleavage (HRC) pattern of the DNA [48] at period $P=3 \mathrm{bp}$, measured over 180-bp interval. In most Hox genes, a HRC3 motif coincides with the homeobox, a sequence encoding the DNA binding domain of these genes, these motifs are also found in multiple intergenic regions within the Hox clusters and other regions of the genome. Analysis of chromatin immunoprecipitation (ChIP-seq) experiments shows that the HRC3 loci show a genome-wide association with binding of histone-modifying enzymes, suggesting that the element may be involved in directing chromatin modifications to specific loci, and thus play a role in regulating Hox gene expression.

The anterior boundaries of Hox expression appear to depend on the somitic number rather than on the original axial positioning [49], therefore it is feasible to speculate that 
the underlying regulatory mechanism is based on digital counting rather than on sensing the level of a morphogen. In this paper I postulate such a direct link that relates the somitic number with the chromatin state. I further describe the most intriguing property of the HRC3 motif: that the number of occurrences of the motif between two consecutive Hox genes corresponds to the number of segments under the control of the anterior gene. I further outline the logic of a possible mechanism of segment counting and explain the role of the HRC3 regulatory element in the process.

\subsection{Analog and digital processes}

There are two main types of control systems: analog and digital. Analog systems where the outputs are continuous functions of input parameters are fast, simple and intuitive, but they are limited in their precision and stability and susceptible to external interference. It is also very difficult to design analog systems capable of executing complex logic. On the other hand, digital or discrete systems are capable of executing complicated tasks, switching between distinct states or modes of operation, and can be stable even in multiple-input-multiple-output designs [50]. Most known dynamical systems in biology are analog in their nature [51], with the notable exceptions of nucleotide sequence replication, transcription and translation that are fully discrete. The process of developmental patterning, including segmental identity, has many properties of a system requiring digital control, such as the high complexity and remarkable stability and reproducibility of the topology of the body plan that is the product of the system.

\section{The segment counter hypothesis}

\subsection{Control of segmental identity: analog or digital?}

Here, I propose that the high robustness and high complexity of the mechanism of segmental identity suggests that a fundamentally digital mechanism plays an important role in the process.

Cells within a developing vertebrate body all have the same genome but they need to perform logical tasks, such as "if I am in segment 19, I should produce a floating rib". To do this, the cells need to first acquire the segmental information, and then use this information to turn on the expression of segment-specific transcription factors (as Hox genes) that will execute the task. The differences between analog and digital control of segmental identity are outlined in Table 1 . The analog model requires only one, purely chemical step, but the process would have to be able to very precisely distinguish between the absolute concentrations of morphogen (such as RA or FGF) characteristic of neighboring segments. With 30-50 segments, the segment-to-segment differences in concentration may be of the order of $2-3 \%$, in other words a $2-3 \%$ error in sensing the concentration will result in the cell executing the developmental program of the wrong segment, potentially leading to a developmental malformation. The required precision may be unreachable for multiple reasons, including cell-to-cell variation resulting from Poissonian noise (error level of 4-5\% assuming 500 morphogen molecules per cell [52]). 
Even if a cell could count all the morphogen molecules within its volume, it might be unable to recognize to which segment it should belong. On the contrary, equipped with a digital counter, a cell would be able to express genes according to its segment number (an integer such as "13" or "22"), rather than to its position along the body axis (e.g." 31\% from the head, 69\% from the tail, $\pm 5 \% ")$.

Also, in analog systems the outputs are continuous functions of inputs, so in a system driven by a gradient of a morphogen, one would expect to find a gradient of Hox gene activity, as opposed to the sharp limits of expression domains that are observed across animal phyla [53-55].

\begin{tabular}{|c|c|}
\hline \multicolumn{2}{|c|}{ Table 1: Models of control of segmental identity } \\
\hline Analog & Digital \\
\hline $\begin{array}{l}\text { Activate a Hox gene if concentration of a } \\
\text { morphogen crosses a specified threshold. }\end{array}$ & $\begin{array}{l}\text { - Acquire segment number information } \\
\text { from environment in a digital form (e.g. } \\
N=19 \text { ). } \\
\text { - Accumulate and store the digital } \\
\text { information. } \\
\text { - Use the information to produce the correct } \\
\text { pattern of gene expression }\end{array}$ \\
\hline $\begin{array}{l}\text { - Conceptually simple but requires highly } \\
\text { precise chemistry to be stable. } \\
\text { - Sharp boundaries of expression domains } \\
\text { are difficult to achieve. }\end{array}$ & $\begin{array}{l}\text { - Complex, multi-stage logic, but the } \\
\text { system is inherently stable and robust. } \\
\text { - Sharp boundaries are natural for a system } \\
\text { built with discrete on/off switches. }\end{array}$ \\
\hline
\end{tabular}

A digital system, built from bi-stable elements that explain the sharp boundaries of expression domains will be resistant to noise, and more robust than any analog mechanism, but an implementation of complex logic is required for such a system to work. Digital systems are less intuitive than analog ones and have not been widely discussed in the context or regulations in development. Below, I will argue that all the components of a digital segment-counting system are present in animal cells, specifically in the cells of the pre-somitic mesoderm (PSM), the embryonic tissue where vertebrate segmentation occurs.

\subsection{The segmental number is accessible to cells in the PSM.}

In vertebrates, segmentation is established during somitogenesis, when precursors of segments, called somites, are produced in the embryo's paraxial mesoderm. Somites are clusters of cells with specific patterns of gene expression that are formed by waves of expression of WNT/Notch and FGF transcripts traveling along the anteroposterior body axis [1, 56-60]. The waves of expression travel from the tail towards the embryo's head. Somites are created sequentially, starting from the anterior end of the PSM, at the locations where the wave stops just before reaching the last previously formed somite. In other words, once a somite has been formed, the waves of expression can no longer travel through its location. Consequently, the number of waves of WNT/Notch/FGF expression 
that have traveled through a location (or the number of times the genes were upregulated) is specific to each somite, and corresponds to the somite's identifying number (counted from the head). A schematic representation of the time-dependent expression of somite genes in different locations along the PSM is shown in Fig. 1. As a consequence of the unique geometry and mechanics of the somitogenesis waves (waves travel back-to-front, but stop in locations front-to-back), during the process of somite formation, a cell has direct access to the information of its segmental number, in a digital form. To know precisely in which segment it is located, it is enough if a cell could count the number of times the genes in WNT or Notch pathways are upregulated.

It is important to note that no other process is known that could provide this information to a cell, either before the onset of somitogenesis or after its completion; outside of somitogenesis, a cell has no known means to "look outside" and count segments between its location and the anterior end of the body. Moreover, tissue transplant experiments, e.g. [61], suggest that segments do indeed acquire their identity during somitogenesis. The role of somitogenesis in coupling between the temporal and spatial patterning has been recently hypothesized by [62], however no specific mechanism has been presented; see also [63-65].

It should also be noted that the general principle underlying somitogenesis, as well as the pathways involved and the overall spatiotemporal structure are both robust and well conserved [1, 49, 56, 57, 59, 66, 67], which makes the somite clock a good candidate background mechanism for the basis of the segmental counter.

\subsection{Counting the Notch peaks: the chromatin abacus.}

I have argued above that a cell in the PSM may acquire the information of segmental identity by counting the peaks of expression of WNT or Notch genes. It still remains to be answered what molecular mechanism may serve as the peak counter within the cell. The most natural implementation of a digital counting device is the abacus; in its simplest form a line of ordered beads that may be in one of two discrete states ("left" or "right"). Here, I propose that a counter using the simple abacus principle may be implemented at the level of chromatin organization.

\subsection{Segment-specific expression of Hox genes.}

I have argued that a segment counter can exist that acquires and remembers the segmental identity of each cell in the PSM by incrementing the counter state (shifting the boundary of active chromatin) each time the somite clock genes are upregulated. In this section I will show that the state of such a counter can be "read" and translated into an expression pattern that is specific to every segment of the body. The basic idea of such a process is outlined in the bottom panel of Fig. 3. Since every subsequent segment has a unique, characteristic profile of open (permissive) chromatin in the counter region, any genes located in this region will be available in specific segments, and blocked in others.

Note that the genes regulated by the counter should be organized in a cluster, and that their order of expression in time as well as along the body would directly correspond to 
their position in the cluster. The collinearity of genes regulated by the digital segmental counter is exactly the same as the collinearity of the Hox genes that has remained a mystery since the genes were discovered. Therefore, I postulate that the "counting chromatin" in vertebrate animals coincides with the clusters of Hox genes, and Hox genes are activated in a segment-specific manner by the counter progressively removing the H3K27me3 marks along the Hox cluster. A boundary of open chromatin in Hox clusters that is progressively repositioned with time during somitogenesis has been observed previously [68], however the resolution of the presented data is insufficient to determine where precisely the boundary is localized at a given time and in a given position along the embryo's axis. If my hypothesis is true, then one would expect to find the check-point loci within the Hox clusters, and their numbers of occurrences would correspond to the number of segments under the control of the specific Hox genes. Specifically, number of checkpoints between two neighboring Hox genes will be equal to the number of segments where the 3' gene is active and the 5' gene remains silenced (see schematic in bottom panel of Fig. 3). 


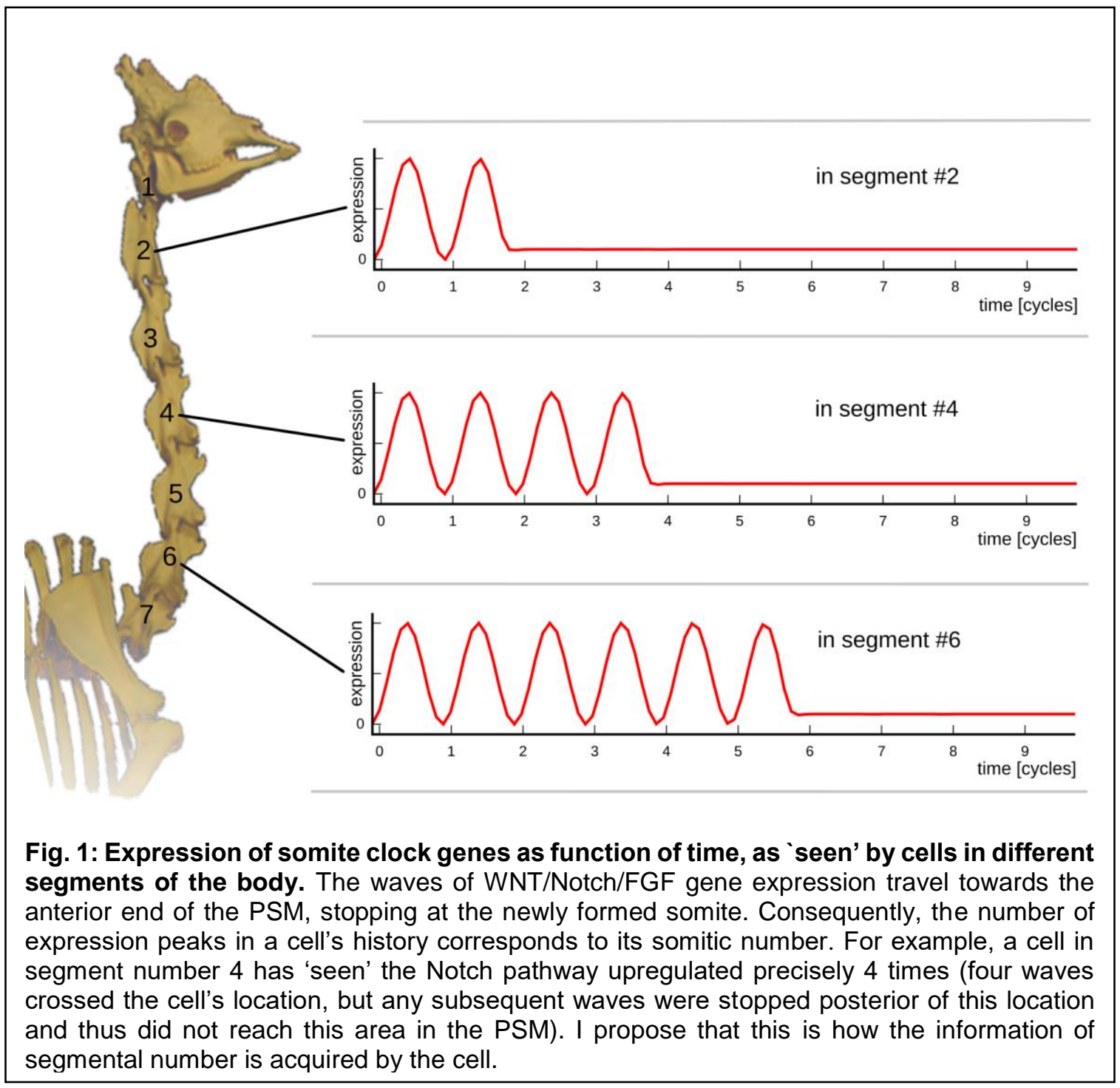


abacus

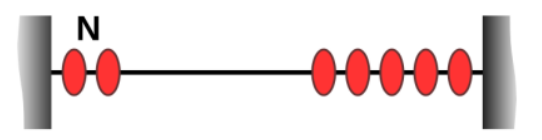

10

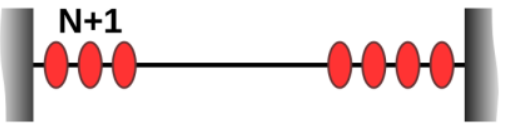

00 abacus beads

\section{chromatin counter}
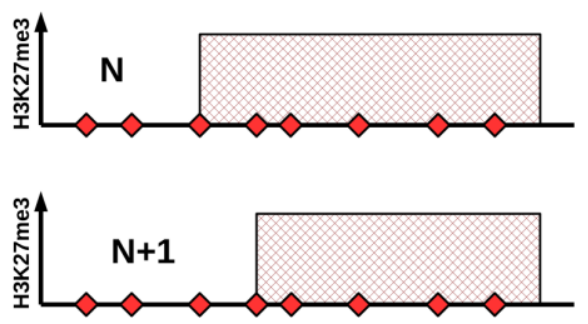

$\diamond \diamond \diamond \begin{aligned} & \text { chromosoma } \\ & \text { checkpoints }\end{aligned}$

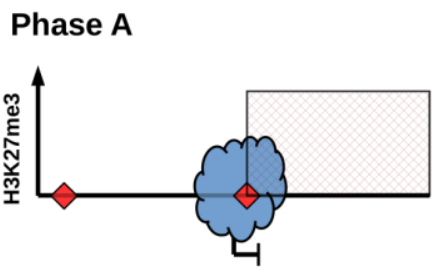

Enzymes stalled on barrier
Phase B

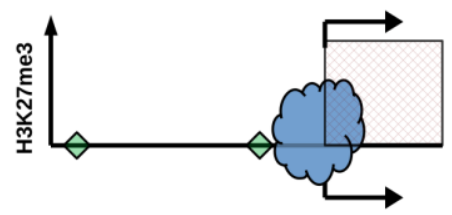

Enzymes can cross barriers

Fig. 2: The principle of chromatin-based counter. As in an abacus (top left), the postulated chromatin counter (top right) stores and processes numbers by switching countable objects between one of two possible states. The function of abacus beads is performed by intervals of DNA sequence, moving the beads between states is equivalent to changing the state of chromatin between active (white) and silenced (shaded) that can be realized by histone $\mathrm{H} 3$ lysine 27 demethylation (top right panel). Note that the model postulates the existence of chromosomal checkpoints, i.e. motifs defining possible locations of the boundary of active chromatin. Bottom: A possible mechanistic scenario. Opening chromatin to next checkpoint may be implemented by demethylating enzymes that are progressing along the chromosome and stall on checkpoint motifs. The barriers can be crossed in one of the phases of the somite cycle, e.g. during the peak of Notch activity.

The postulated mechanism requires that the chromosomal region involved in segment counting contains pre-defined "check-points", i.e. specific loci that may serve as boundary of active chromatin. The boundary progressing to the next checkpoint would then be equivalent to shifting one abacus bead from right to left, or incrementing the segment counter (performing the $\mathrm{N}:=\mathrm{N}+1$ arithmetic operation). With discrete check-points, the counter is truly digital, i.e. it operates on integers rather than on continuous variables. A schematic view of such mechanism is shown in Figure 2 and in top panel of Figure 3 . The biophysical details of the mechanism are yet to be elucidated; the underlying principle may be based on the H3K27 demethylation machinery opening chromatin while progressing along the chromosome, and stalling on barrier checkpoints. The barriers can be crossed only during one of the phases of the somite cycle, possibly during high activity of the Notch pathway, see bottom panel of Figure 2. Such stop-and-release mechanism can assure that exactly one checkpoint is crossed at each peak of Notch expression. Below (section 2.5) I will present evidence that the newly discovered HRC3 motifs are likely acting as the postulated chromosomal check-points. 
Segments are added by traveling waves of cyclic WNT/Notch/FGF expression

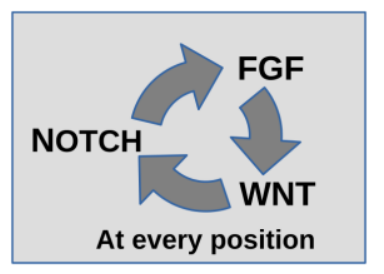

Somite

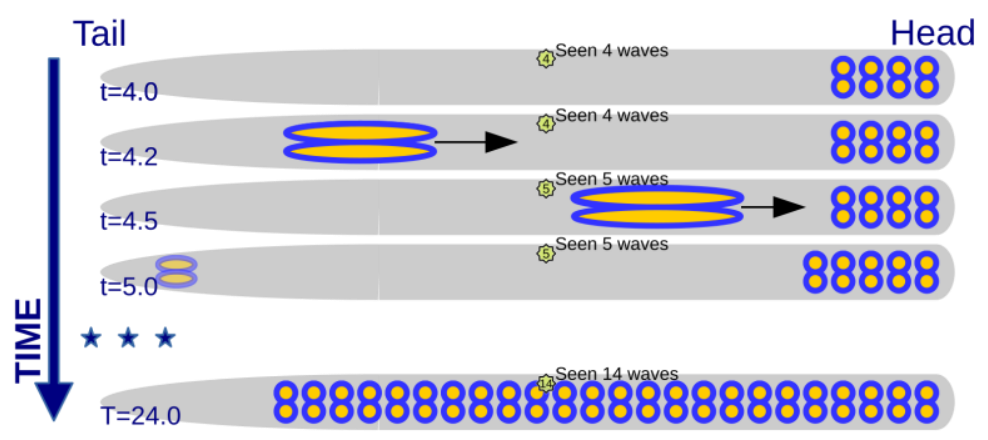

A cell in the PSM knows its segment number by counting waves that have passed through it

\section{Segmentation controls sites of sequential histone modifications in Hox clusters}

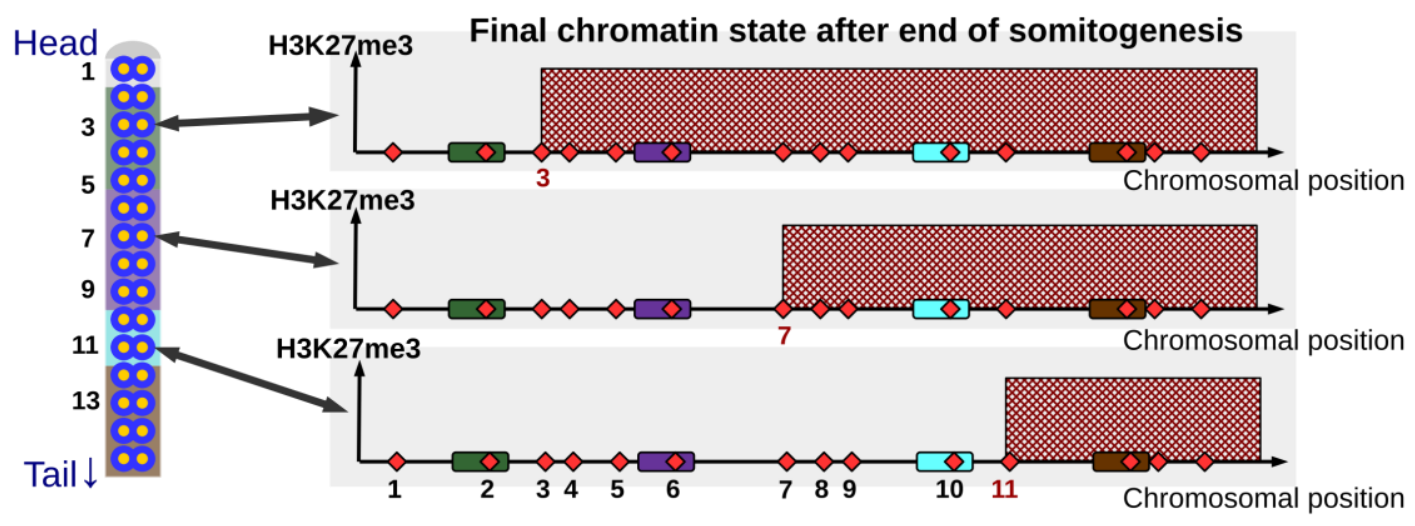

\section{Next HRC3 motif marks new boundary of open chromatin}

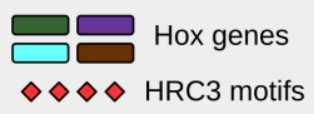

Fig. 3: The proposed logic of epigenetic changes regulating Hox genes along the anteroposterior body axis. Top panel: Cells can "know" their numerical segment identity by counting waves of WNT/Notch/FGF activity. Each cycle moves the boundary of open chromatin to the next HRC3 motif. Bottom: the process leads to imprinting of the segmental identity into the cells of the pre-somitic mesoderm that allows activation of segment-specific Hox genes. The epigenetic state of a Hox cluster at the end of somitogenesis if shown for three locations along the PSM.

\subsection{The HRC3 motif as the chromosomal check-point.}

I have outlined a mechanism of establishing segment-specific gene expression patterns; the postulated process would require check-point loci in multiple positions within the Hox clusters; the check-points acting as boundaries of active chromatin fixed between peaks of Notch activity. The above properties of the check-point match the characteristics of the recently discovered HRC3 signature. 
Additional evidence supporting the hypothesis comes from a search for sequences with the HRC3 signature in all locations along the Hox clusters, both coding and non-coding. The finding (based on applying the definition in [43] to every position in the Hox clusters) has revealed that several dozen HRC3 motifs are found in each human and mouse Hox cluster (Fig. 4). The numbers of HRC3 motifs (red) between neighboring genes are generally conserved between clusters and agree with the numbers of segments under the control of each gene, or more precisely to numbers of segments between anterior boundaries of the expression domains of these genes. For example, seven HRC3's are present between Hox4 and Hox6 in clusters A, B and C, which may correspond to the seven cervical vertebrae.

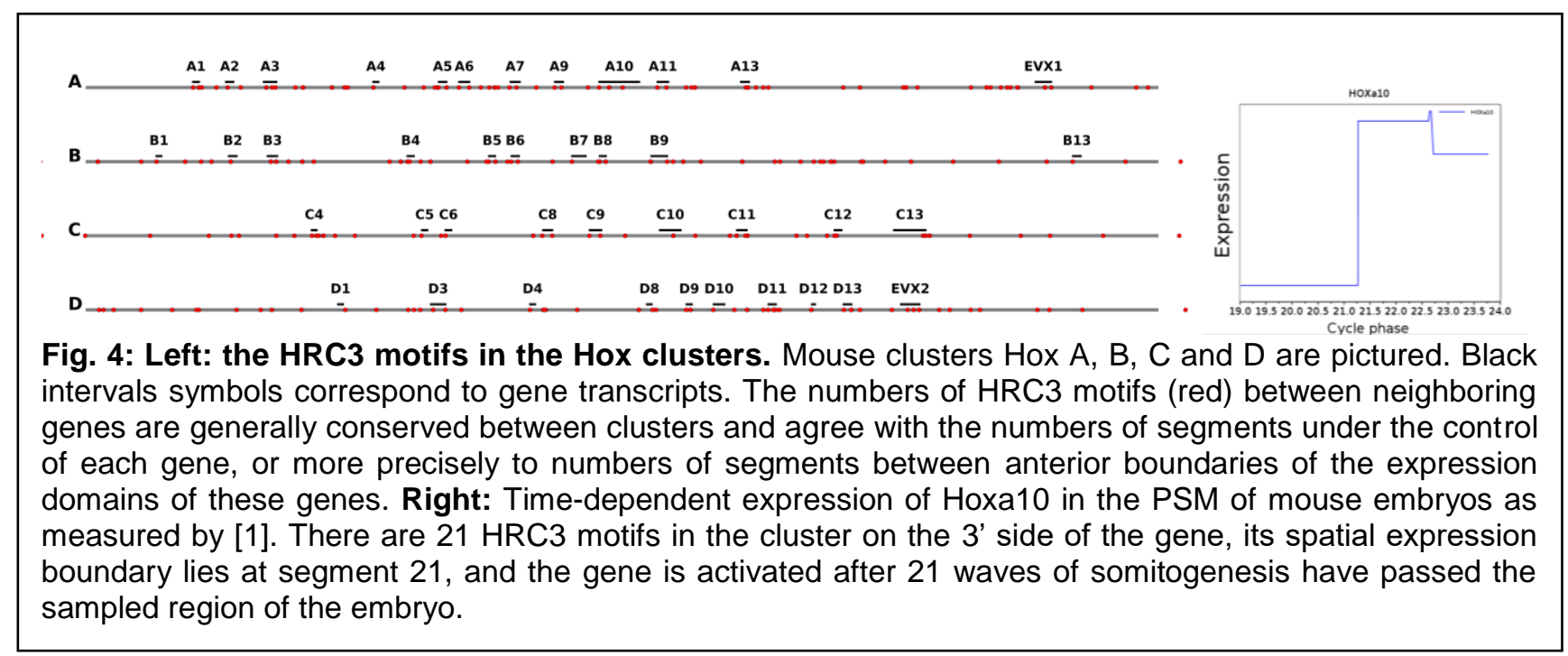

Moreover, the hypothesis agrees with the gene expression profiles observed in the PSM. For example, Hox10 is activated in the PSM during the 21 st oscillation of the somite clock (see right panel of Fig. 4 plotted based on the data of [1]), which agrees with its expression boundary after somitogenesis (at L1 or segment 21 , see [69]), and the $21^{\text {st }}$ consecutive HRC3 motif located within the gene's coding sequence and with 21 HRC3 motifs between the 3 ' end of the HoxA cluster and the HoxA10 transcript.

These findings strongly support the central hypothesis of this paper. It has allowed to devise a model of epigenetic regulation during embryonic development, in which the HRC3 motif acts as an 'address' to which the histone modifications are directed that mark transcriptionally active chromatin. Within the Hox clusters, chromatin is sequentially opened over an interval from the current boundary to the next HRC3 motif upon stimulation of the Wnt-Notch-Fgf pathways [59]. This model correctly predicts the numbers of segments in the vertebrate body and explains co-linearity of Hox genes and other developmental TFs. 


\section{Evolvability of segmental numbers}

I have shown how a single Hox cluster can implement a somite/segment counter in a vertebrate animal. It appears that a simple mutation, such as deletion or duplication of a counting motif, would result in a change in the number of vertebrae, something that is not typically observed in nature.

Most deuterostome genomes, including mammals, contain however not one but four (land vertebrates) or seven (teleost fish) clusters of Hox genes. In an animal with multiple Hox clusters, if a mutation occurs that deactivates an existing HRC3 motif, or introduces an additional one through duplication, the change will affect only one cluster of Hox genes. As a result, the expression patterns of Hox genes from different clusters would lose their synchrony, for example a cell would express genes dependent on HoxA according to the program for segment 19, but genes dependent on HoxB, HoxC and HoxD as in segment 20 [see schematic in Fig. 5], likely leading to detrimental or lethal developmental defects that put such mutant at a strong evolutionary disadvantage. A rescuing mutation in each remaining Hox cluster would be required to fully restore the synchronization of Hox expression domains. This may explain why the segmental numbers are generally very well preserved in the animal kingdom, or at least among vertebrates: a simultaneous quadruple mutation changing the number of segments without significant detrimental effects is highly unlikely. The explanation can also account for the fact that the conservation is much stronger in the anterior part of the body - a mutation changing the number of checkpoint motifs would affect gene expression in every segment posterior to such mutation. In the archetypal example of segmental number conservation (the 7 cervical vertebrae in mammals) only a few exceptions are known (sloths, sirenians), and these animals show significant changes affecting their anterior body plan and limbs / digits. Such pleiotropic effects are also observed in humans suffering from a developmental defect [70]. For example, a cervical rib [71] is often associated with missing $12^{\text {th }}$ rib [72] and with L5 sacralization [73], that can be explained by partial (heterozygotic) loss of function of one of the checkpoint motifs. Strong associations between malformations of the different organ systems and vertebral patterns have been observed. In an anatomical study of miscarried fetuses, only $20.6 \%$ of 1,062 diseased human fetuses had a normal vertebral pattern [74]. The expression pattern of Hox genes is important not only for establishing the skeletal features, but also for other organs. Indeed, skeletal developmental abnormalities are often associated with cancer [72], which is consistent with the pleiotropic effects of a shift in Hox gene expression domains, and the fact that tumors of different types have the characteristics of aberrant cellular development [75-77]. Note that in many experiments involving viable artificial Hox mutants, the function of the Hox gene is lost, but the HRC3 motif associated with the gene remains intact, and the experiment results in a homeotic transformation without a homeotic shift, leaving the number of segments remains unaffected [78-80]. 

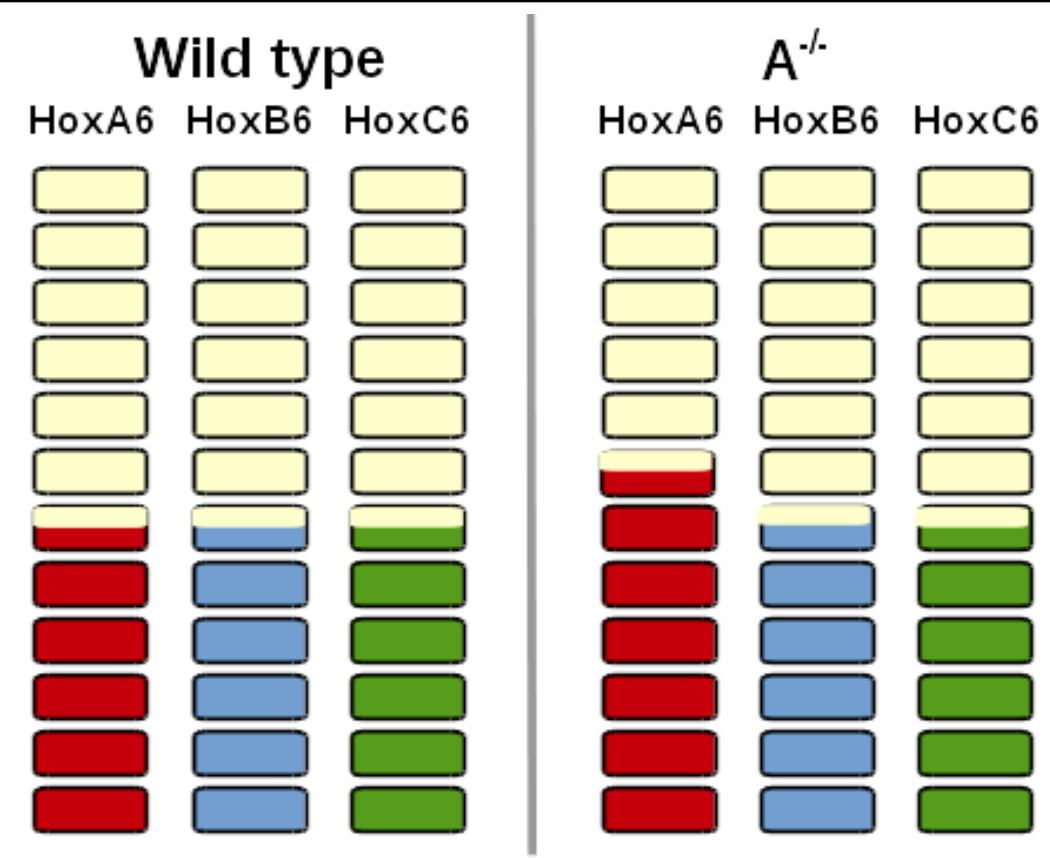

Fig. 5: The expected changes in profiles of Hox6 genes following deletion of one HRC3 motif in HoxA cluster. The Hox gene expression in the cluster with deletion is shifted rostrally by one somite after deletion, leading to loss of synchrony between the clusters.

\section{Possible tests of the counter hypothesis.}

The model of somite counter presented in this paper leads to numerous predictions and can be tested experimentally in a number of ways. First, the progression of the boundary of the active chromatin to the next HRC3 motif should be measurable by differential singlecell ChIP-seq of PSM samples at different somitic numbers. Second, deleting or duplicating HRC3 motifs in non-coding locations are expected to lead to homeotic shifts and predictable developmental malformations; the effects should be observable by multichannel fluorescent in-situ hybridization (FISH) to detect changes in anterior boundaries of Hox gene expression domains in embryos after completing somitogenesis stage. Finally, a quadruple, homozygotic deletion of a non-coding checkpoint motif in every Hox cluster is expected to produce a fully viable animal, but with a reduced number of segments. While such mutant would require multiple generations of breeding and genotyping conditionally induced deletions, it would result in a colony of mice with six cervical vertebrae, most likely unable to produce viable offspring with wild-type animals (if deleted non-coding motifs 3' of Hox6): technically a new species with an artificially designed body plan. 


\section{Conclusions:}

In this paper, I presented a new hypothesis of an integrated primordial mechanism that explains several aspects of development, conservation of synteny, genome organization and evolution. The hypothesis is especially attractive in that it is based on one mechanism accounting for all these aspects at the same time; such parsimony is often a signature of successful theories $[81,82]$. The outline of the proposed mechanism can be summarized in the following steps:

i. Acquiring segmental identity. The identity of the segment is directly available to any cell in a vertebrate's somitic mesoderm. The numerical segmental identity (e.g. "segment number 19") is determined by the number of somitogenesis waves that had travelled through the cell. Each somite wave is associated with a strong peak of Notch activity.

ii. Cells remembering their segmental identity by counting somites. The segment identity can be digitally encoded as the information is stored in the state of chromatin, if a chromatin mark progresses to a next checkpoint (the next HRC3 motif) along the chromosome with each peak of the Notch pathway.

iii. Translate segmental identity to the body plan. This process progresses along the Hox cluster, and it produces a pattern of chromatin state specific to every segment, these patterns are in turn directly translated to activating specific Hox genes in specific segments.

The postulated mechanism can work only if the Hox genes are colinear within their clusters; my hypothesis is the first one to explain the evolutionary pressure on maintaining the collinearity of Hox genes that has remained a mystery since the Hox clusters were discovered 40 years ago [12].

The distribution of the HRC3 motifs in the Hox clusters directly translates to the numbers of repeats of structures in the body plan. Specifically, from the genomic sequence alone we can now directly predict the numbers of cervical and thoracic vertebrae in a vertebrate's body. This suggests that this aspect of development is indeed digital, or computable. It is then likely that a similar digital mechanism of directing chromatin modifications to the specific loci may explain other aspects of the body plan and of development in general, supporting the notion of a computable embryo [2, 83, 84]. Specifically, coupling a biomolecular oscillator to developmental patterning and cell fate may be responsible not only for metameric segmentation, but also for other aspects of morphogenesis, as patterning of limbs and neurogenesis [85-90].

The association of HRC3 motifs with developmental transcription factors also outside the Hox clusters and also in invertebrates suggests that a version of such "computable embryo" theory might also apply to other aspects of evolutionary developmental biology, and may lead to solving other open questions, such as the origin of larval forms, the nature of the protostomal-deuterostomal ancestry, and others. 


\section{Acknowledgment}

The author thanks Alessandro Minelli, Robb Krumlauf, and Zbyszek Otwinowski for helpful comments and discussions.

\section{Bibliography}

1. Dequeant ML, Glynn E, Gaudenz K, Wahl M, Chen J, Mushegian A, et al. A complex oscillating network of signaling genes underlies the mouse segmentation clock. Science. 2006;314(5805):1595-8. doi: DOI 10.1126/science.1133141. PubMed PMID: ISI:000242624600041.

2. Minelli A. Forms of Becoming: The Evolutionary Biology of Development: Princeton University Press; 2009.

3. Richardson MK, Allen SP, Wright GM, Raynaud A, Hanken J. Somite number and vertebrate evolution. Development. 1998;125(2):151-60. PubMed PMID: ISI:000072046900001.

4. Galis F. Why do almost all mammals have seven cervical vertebrae? developmental constraints, Hox genes, and cancer. Journal of Experimental Zoology. 1999;285(1):19-26. doi: Doi 10.1002/(Sici)1097-010x(19990415)285:1<19::AidJez3>3.0.Co;2-Z. PubMed PMID: ISI:000080086100003.

5. Cooke J. Control of Somite Number during Morphogenesis of a Vertebrate, Xenopus-Laevis. Nature. 1975;254(5497):196-9. doi: Doi 10.1038/254196a0. PubMed PMID: ISI:A1975V885500019.

6. Waddington $\mathrm{CH}$, Deuchar EM. Studies on the Mechanism of Meristic Segmentation .1. The Dimensions of Somites. Journal of Embryology and Experimental Morphology. 1953;1(4):349-56. PubMed PMID: ISI:A1953YD48400002.

7. British Society for Developmental Biology., Ede DA, Hinchliffe JR, Balls M. Vertebrate limb and somite morphogenesis : the third symposium of the British Society for Developmental Biology. Cambridge [Eng.] ; New York: Cambridge University Press; 1977. 498 p. p.

8. Flint OP, Ede DA, Wilby OK, Proctor J. Control of Somite Number in Normal and Amputated Mutant Mouse Embryos - Experimental and a Theoretical-Analysis. Journal of Embryology and Experimental Morphology. 1978;45(Jun):189-202. PubMed PMID: ISI:A1978FF00700013.

9. Resende TP, Ferreira M, Teillet MA, Tavares AT, Andrade RP, Palmeirim I. Sonic hedgehog in temporal control of somite formation. Proc Natl Acad Sci U S A. 107(29):12907-12. Epub 2010/07/10. doi: 1000979107 [pii] 10.1073/pnas.1000979107. PubMed PMID: 20615943; PubMed Central PMCID: PMC2919945.

10. Iimura T, Denans N, Pourquie O. Establishment of Hox vertebral identities in the embryonic spine precursors. Curr Top Dev Biol. 2009;88:201-34. doi: 10.1016/S0070-2153(09)88007-1. PubMed PMID: 19651306; PubMed Central PMCID: PMCPMC3523337. 
11. Gomez C, Ozbudak EM, Wunderlich J, Baumann D, Lewis J, Pourquie O. Control of segment number in vertebrate embryos. Nature. 2008;454(7202):335-9. doi: 10.1038/nature07020. PubMed PMID: ISI:000257665300039.

12. Lewis EB. Gene Complex Controlling Segmentation in Drosophila. Nature. 1978;276(5688):565-70. PubMed PMID: ISI:A1978FZ26600029.

13. Gehring WJ, Affolter M, Burglin T. Homeodomain Proteins. Annu Rev Biochem. 1994;63:487-526. PubMed PMID: ISI:A1994NV05900015.

14. Mcginnis W, Levine MS, Hafen E, Kuroiwa A, Gehring WJ. A Conserved DNASequence in Homoeotic Genes of the Drosophila Antennapedia and Bithorax Complexes. Nature. 1984;308(5958):428-33. PubMed PMID: ISI:A1984SJ97500042. 15. Carapuco M, Novoa A, Bobola N, Mallo M. Hox genes specify vertebral types in the presomitic mesoderm. Genes \& Development. 2005;19(18):2116-21. doi: Doi 10.1101/Gad.338705. PubMed PMID: ISI:000231929100004.

16. Manzanares M, Cordes S, Ariza-McNaughton L, Sadl V, Maruthainar K, Barsh $\mathrm{G}$, et al. Conserved and distinct roles of kreisler in regulation of the paralogous Hoxa3 and Hoxb3 genes. Development. 1999;126(4):759-69. PubMed PMID: ISI:000079085700015.

17. Manzanares M, Bel-Vialar S, Ariza-McNaughton L, Ferretti E, Marshall H, Maconochie MM, et al. Independent regulation of initiation and maintenance phases of Hoxa3 expression in the vertebrate hindbrain involve auto- and cross-regulatory mechanisms. Development. 2001;128(18):3595-607. PubMed PMID:

ISI:000171505200018.

18. Prince VE. Hox genes and segmental patterning of the vertebrate hindbrain. Am Zool. 1998;38(4):634-46. PubMed PMID: ISI:000076265300005.

19. Wellik DM. Hox patterning of the vertebrate axial skeleton. Developmental Dynamics. 2007;236(9):2454-63. PubMed PMID: ISI:000249539700009.

20. McIntyre DC, Rakshit S, Yallowitz AR, Loken L, Jeannotte L, Capecchi MR, et al. Hox patterning of the vertebrate rib cage. Development. 2007;134(16):2981-9. doi: Doi 10.1242/Dev.007567. PubMed PMID: ISI:000248385000010.

21. Burke AC. Hox genes and the global patterning of the somitic mesoderm. Current Topics in Developmental Biology, Vol 47. 2000;47:155-81. PubMed PMID: ISI:000087771100006.

22. Mallo M, Wellik DM, Deschamps J. Hox genes and regional patterning of the vertebrate body plan. Dev Biol. 2010;344(1):7-15. doi: DOI 10.1016/j.ydbio.2010.04.024. PubMed PMID: ISI:000280426400002.

23. Gaunt SJ. The significance of Hox gene collinearity. Int J Dev Biol. 2015;59(46):159-70. doi: 10.1387/ijdb.150223sg. PubMed PMID: 26260684.

24. Durston AJ. Two Tier Hox Collinearity Mediates Vertebrate Axial Patterning. Front Cell Dev Biol. 2018;6:102. doi: 10.3389/fcell.2018.00102. PubMed PMID: 30234110; PubMed Central PMCID: PMCPMC6131192.

25. Durston AJ. Vertebrate hox temporal collinearity: does it exist and what is it's function? Cell Cycle. 2019;18(5):523-30. doi: 10.1080/15384101.2019.1577652. PubMed PMID: 30712443; PubMed Central PMCID: PMCPMC6464588.

26. Gehring WJ, Kloter U, Suga H. Evolution of the Hox Gene Complex from an Evolutionary Ground State. Curr Top Dev Biol. 2009;88:35-61. PubMed PMID: ISI:000268505300002. 
27. Durston AJ. Global posterior prevalence is unique to vertebrates: A dance to the music of time? Developmental Dynamics. 2012;241(11):1799-807. PubMed PMID: ISI:000310285300013.

28. Fraser P, Bickmore W. Nuclear organization of the genome and the potential for gene regulation. Nature. 2007;447(7143):413-7. PubMed PMID: ISI:000246693100036.

29. Chambeyron S, Bickmore WA. Chromatin decondensation and nuclear reorganization of the HoxB locus upon induction of transcription. Genes \& Development. 2004;18(10):1119-30. PubMed PMID: ISI:000221591300002.

30. Soshnikova N, Duboule D. Epigenetic Temporal Control of Mouse Hox Genes in Vivo. Science. 2009;324(5932):1320-3. doi: DOI 10.1126/science.1171468. PubMed PMID: ISI:000266635100044.

31. Lee MG, Villa R, Trojer P, Norman J, Yan KP, Reinberg D, et al. Demethylation of H3K27 regulates polycomb recruitment and H2A ubiquitination. Science. 2007;318(5849):447-50. doi: DOI 10.1126/science.1149042. PubMed PMID: ISI:000250230400046.

32. Agger K, Cloos PAC, Christensen J, Pasini D, Rose S, Rappsilber J, et al. UTX and JMJD3 are histone H3K27 demethylases involved in HOX gene regulation and development. Nature. 2007;449(7163):731-U10. doi: Doi 10.1038/Nature06145. PubMed PMID: ISI:000250045000046.

33. Nottke A, Colaiacovo MP, Shi Y. Developmental roles of the histone lysine demethylases. Development. 2009;136(6):879-89. doi: 10.1242/dev.020966. PubMed PMID: ISI:000263558100001.

34. Guerreiro I, Nunes A, Woltering JM, Casaca A, Novoa A, Vinagre T, et al. Role of a polymorphism in a Hox/Pax-responsive enhancer in the evolution of the vertebrate spine. Proceedings of the National Academy of Sciences of the United States of America. 2013;110(26):10682-6. PubMed PMID: ISI:000321503700056.

35. Lonfat N, Montavon T, Darbellay F, Gitto S, Duboule D. Convergent evolution of complex

regulatory landscapes and

pleiotropy at Hox loci. Science. 2014;346(6212):1004-6.

36. Montavon T, Duboule D. Chromatin organization and global regulation of Hox gene clusters. Philosophical Transactions of the Royal Society B-Biological Sciences. 2013;368(1620). doi: Artn 20120367

10.1098/Rstb.2012.0367. PubMed PMID: ISI:000318614800009.

37. Schorderet P, Duboule D. Structural and Functional Differences in the Long Non-Coding RNA Hotair in Mouse and Human. Plos Genetics. 2011;7(5). doi: ARTN e1002071

DOI 10.1371/journal.pgen.1002071. PubMed PMID: ISI:000291014600017.

38. Woltering JM, Duboule D. The Origin of Digits: Expression Patterns versus Regulatory Mechanisms. Dev Cell. 2010;18(4):526-32. PubMed PMID:

ISI:000277105800006.

39. Kmita M, Duboule D. Organizing axes in time and space; 25 years of colinear tinkering. Science. 2003;301(5631):331-3. doi: 10.1126/science.1085753. PubMed PMID: 12869751. 
40. Odom DT, Dowell RD, Jacobsen ES, Gordon W, Danford TW, MacIsaac KD, et al. Tissue-specific transcriptional regulation has diverged significantly between human and mouse. Nature Genetics. 2007;39(6):730-2. doi: 10.1038/ng2047. PubMed PMID: ISI:000246859100016.

41. de Laat W, Duboule D. Topology of mammalian developmental enhancers and their regulatory landscapes. Nature. 2013;502(7472):499-506. doi:

10.1038/nature12753. PubMed PMID: ISI:000325988400044.

42. Soshnikova N, Montavon T, Leleu M, Galjart N, Duboule D. Functional Analysis of CTCF During Mammalian Limb Development. Dev Cell. 2010;19(6):81930. doi: 10.1016/j.devcel.2010.11.009. PubMed PMID: ISI:000285450200008. 43. Fongang B, Kong F, Negi S, Braun W, Kudlicki A. A Conserved Structural Signature of the Homeobox Coding DNA in HOX genes. Sci Rep. 2016;6:35415. doi: 10.1038/srep35415. PubMed PMID: 27739488; PubMed Central PMCID: PMCPMC5064350.

44. Fisher. Tests of significance in harmonic analysis. Proc Roy Soc Ser A. 1929;125:54-9.

45. Lomb NR. Least-Squares Frequency-Analysis of Unequally Spaced Data. Astrophysics and Space Science. 1976;39(2):447-62. PubMed PMID: ISI:A1976BK74400015.

46. Kudlicki A, Rowicka, M \& Otwinowski, Z. Significance-testing of periodogram for short time series. Proceedings of the 2008 International Conference on Bioinformatics and Computational Biology. 2008:424-30.

47. Schuster A. On the investigation of hidden periodicities with application to a supposed 26 day period of meteorological phenomena. Terrestrial Magnetism and Atmospheric Electricity. 1898;3:13-41.

48. Bishop EP, Rohs R, Parker SCJ, West SM, Liu P, Mann RS, et al. A Map of Minor Groove Shape and Electrostatic Potential from Hydroxyl Radical Cleavage Patterns of DNA. Acs Chemical Biology. 2011;6(12):1314-20. doi: Doi 10.1021/Cb200155t. PubMed PMID: ISI:000298024500002.

49. Dubrulle J, McGrew MJ, Pourquie O. FGF signaling controls somite boundary position and regulates segmentation clock control of spatiotemporal Hox gene activation. Cell. 2001;106(2):219-32. doi: Doi 10.1016/S0092-8674(01)00437-8. PubMed PMID: ISI:000170193100011.

50. Franklin GF, Powell JD, Workman ML. Digital control of dynamic systems. 3rd ed. Menlo Park, Calif.: Addison-Wesley; 1998. xxiii, 742 p. p.

51. Sree Hari Rao V, Raja Sekhara Rao P. Dynamic models and control of biological systems. Dordrecht ; New York: Springer; 2009. xiii, 275 p. p.

52. Little SC, Tikhonov M, Gregor T. Precise developmental gene expression arises from globally stochastic transcriptional activity. Cell. 2013;154(4):789-800. doi: 10.1016/j.cell.2013.07.025. PubMed PMID: 23953111; PubMed Central PMCID: PMCPMC3778922.

53. Dressler GR, Gruss P. Anterior boundaries of Hox gene expression in mesoderm-derived structures correlate with the linear gene order along the chromosome. Differentiation. 1989;41(3):193-201. PubMed PMID: 2575552. 
54. Mallo M, Alonso CR. The regulation of Hox gene expression during animal development. Development. 2013;140(19):3951-63. doi: 10.1242/dev.068346. PubMed PMID: 24046316.

55. Goldbeter A, Gonze D, Pourquie O. Sharp developmental thresholds defined through bistability by antagonistic gradients of retinoic acid and FGF signaling. Dev Dyn. 2007;236(6):1495-508. doi: 10.1002/dvdy.21193. PubMed PMID: 17497689.

56. Krol AJ, Roellig D, Dequeant ML, Tassy O, Glynn E, Hattem G, et al. Evolutionary plasticity of segmentation clock networks. Development. 2011;138(13):2783-92. doi: Doi 10.1242/Dev.063834. PubMed PMID: ISI:000291348700015.

57. Dequeant ML, Ahnert S, Edelsbrunner H, Fink TMA, Glynn EF, Hattem G, et al. Comparison of Pattern Detection Methods in Microarray Time Series of the Segmentation Clock. Plos One. 2008;3(8). doi: Artn E2856

Doi 10.1371/Journal.Pone.0002856. PubMed PMID: ISI:000264366600012. 58. Palmeirim I, Henrique D, Pourquie O. Evidence for a molecular clock underlying avian somitogenesis. Dev Biol. 1997;186(2):B86-B. PubMed PMID: ISI:A1997XH77400469.

59. Fongang B, Kudlicki A. The precise timeline of transcriptional regulation reveals causation in mouse somitogenesis network. Bmc Dev Biol. 2013;13. PubMed PMID: ISI:000328449800001.

60. Fongang B, Kudlicki A. Comparison between Timelines of Transcriptional Regulation in Mammals, Birds, and Teleost Fish Somitogenesis. PLoS One. 11(5):e0155802. Epub 2016/05/19. doi: 10.1371/journal.pone.0155802 PONE-D-16-08730 [pii]. PubMed PMID: 27192554; PubMed Central PMCID: PMC4871587.

61. Narayana.Ch, Hamburge.V. Motility in Chick Embryos with Substitution of Lumbosacral by Brachial and Brachial by Lumbosacral Spinal Cord Segments. Journal of Experimental Zoology. 1971;178(4):415-\&. doi: DOI 10.1002/jez.1401780402. PubMed PMID: ISI:A1971K975500001.

62. Durston AJ, Wacker S, Bardine N, Jansen HJ. Time Space Translation: A Hox Mechanism for Vertebrate A-P Patterning. Curr Genomics. 2012;13(4):300-7. PubMed PMID: WOS:000305297800005.

63. Durston AJ, Jansen HJ, Rieden PID, Hooiveld MHW. Hox collinearity - a new perspective (vol 55, pg 899, 2011). Int J Dev Biol. 2012;56(4):311-+. doi: 10.1387/ijdb.113358ad. PubMed PMID: WOS:000307800100012.

64. Durston AJ. Time, space and the vertebrate body axis. Semin Cell Dev Biol. 2015;42:66-77. doi: 10.1016/j.semcdb.2015.05.005. PubMed PMID: 26003049. 65. Durston AJ, Zhu K. A time space translation hypothesis for vertebrate axial patterning. Semin Cell Dev Biol. 2015;42:86-93. doi: 10.1016/j.semcdb.2015.06.001. PubMed PMID: 26051324.

66. Pourquie 0, Kusumi K. When body segmentation goes wrong. Clinical Genetics. 2001;60(6):409-16. doi: DOI 10.1034/j.1399-0004.2001.600602.x. PubMed PMID: ISI:000173490400002.

67. Fongang B, Kudlicki A. Comparison between Timelines of Transcriptional Regulation in Mammals, Birds, and Teleost Fish Somitogenesis. PLoS One. 2016;11(5). doi: ARTN e0155802 
10.1371/journal.pone.0155802. PubMed PMID: ISI:000376286100097.

68. Soshnikova N, Duboule D. Epigenetic control of hox genes collinear activation during vertebrate development. Mechanisms of Development. 2009;126:S6-S7. doi: DOI 10.1016/j.mod.2009.06.956. PubMed PMID: ISI:000270034900018.

69. Wellik DM. Hox genes and vertebrate axial pattern. Curr Top Dev Biol. 2009;88:257-78. doi: 10.1016/S0070-2153(09)88009-5. PubMed PMID: 19651308. 70. Galis F, Metz JA. Evolutionary novelties: the making and breaking of pleiotropic constraints. Integr Comp Biol. 2007;47(3):409-19. doi: 10.1093/icb/icm081. PubMed PMID: 21672849.

71. Spadlinski L, Cecot T, Majos A, Stefanczyk L, Pietruszewska W, Wysiadecki G, et al. The Epidemiological, Morphological, and Clinical Aspects of the Cervical Ribs in Humans. Biomed Res Int. 2016;2016:8034613. doi: 10.1155/2016/8034613. PubMed PMID: 27975060; PubMed Central PMCID: PMCPMC5126392 has any competing interests.

72. Bots J, Wijnaendts LC, Delen S, Van Dongen S, Heikinheimo K, Galis F. Analysis of cervical ribs in a series of human fetuses. J Anat. 2011;219(3):403-9. doi: 10.1111/j.1469-7580.2011.01400.x. PubMed PMID: 21689099; PubMed Central PMCID: PMCPMC3171776.

73. Erken E, Ozer HT, Gulek B, Durgun B. The association between cervical rib and sacralization. Spine (Phila Pa 1976). 2002;27(15):1659-64. PubMed PMID: 12163729.

74. Ten Broek CM, Bakker AJ, Varela-Lasheras I, Bugiani M, Van Dongen S, Galis F. Evo-Devo of the Human Vertebral Column: On Homeotic Transformations, Pathologies and Prenatal Selection. Evol Biol. 2012;39(4):456-71. doi: 10.1007/s11692-012-9196-1. PubMed PMID: 23226903; PubMed Central PMCID: PMCPMC3514701.

75. Virchow RL. Cellular Pathology. 1859 special ed. London, UK: John Churchill. 1978:204-7.

76. Ben-Porath I, Thomson MW, Carey VJ, Ge R, Bell GW, Regev A, et al. An embryonic stem cell-like gene expression signature in poorly differentiated aggressive human tumors. Nat Genet. 2008;40(5):499-507. doi: 10.1038/ng.127. PubMed PMID: 18443585; PubMed Central PMCID: PMCPMC2912221.

77. Bertrand FE, Angus CW, Partis WJ, Sigounas G. Developmental pathways in colon cancer: crosstalk between WNT, BMP, Hedgehog and Notch. Cell Cycle. 2012;11(23):4344-51. doi: 10.4161/cc.22134. PubMed PMID: 23032367; PubMed Central PMCID: PMCPMC3552917.

78. Small KM, Potter SS. Homeotic Transformations and Limb Defects in Hox-A11 Mutant Mice. Genes \& Development. 1993;7(12A):2318-28. doi: DOI 10.1101/gad.7.12a.2318. PubMed PMID: ISI:A1993ML38100005.

79. Wahba GM, Hostikka SL, Carpenter EM. The paralogous Hox genes Hoxa10 and Hoxd10 interact to pattern the mouse hindlimb peripheral nervous system and skeleton. Dev Biol. 2001;231(1):87-102. doi: DOI 10.1006/dbio.2000.0130. PubMed PMID: ISI:000167271000007.

80. Davis AP, Witte DP, Hsiehli HM, Potter SS, Capecchi MR. Absence of Radius and Ulna in Mice Lacking Hoxa-11 and Hoxd-11. Nature. 1995;375(6534):791-5. doi: Doi 10.1038/375791a0. PubMed PMID: ISI:A1995RF98900079. 
81. Ockhamus W. Quaestiones et decisiones in quattuor libros Sententiarum Petri Lombardi Editione Lugdunensi, 1495. 1495;i, dist. 27, qu. 2, K., http://www.liburuklik.euskadi.net/handle/10771/11892 page 114(27).

82. Barnes EC. Ockham's razor and the anti-superfluity principle (Principle of parsimony). Erkenntnis. 2000;53(3):353-74. doi: Doi 10.1023/A:1026464713182. PubMed PMID: ISI:000166205000004.

83. Rosenberg A. Reductionism redux: Computing the embryo. Biology \& Philosophy. 1997;12(4):445-70. doi: Doi 10.1023/A:1006574719901. PubMed PMID: ISI:A1997YB35400001.

84. Robert JS. Embryology, Epigenesis and Evolution: Taking Development Seriously. 2004 ed: Cambridge University Press, 2004; 2004.

85. Sheeba CJ, Andrade RP, Palmeirim I. Limb patterning: from signaling gradients to molecular oscillations. J Mol Biol. 2014;426(4):780-4. doi: 10.1016/j.jmb.2013.11.022. PubMed PMID: 24316003.

86. Pascoal S, Carvalho CR, Rodriguez-Leon J, Delfini MC, Duprez D, Thorsteinsdottir $S$, et al. A molecular clock operates during chick autopod proximaldistal outgrowth. J Mol Biol. 2007;368(2):303-9. doi: 10.1016/j.jmb.2007.01.089. PubMed PMID: 17346744.

87. Sheeba CJ, Andrade RP, Palmeirim I. Mechanisms of vertebrate embryo segmentation: Common themes in trunk and limb development. Semin Cell Dev Biol. 2016;49:125-34. doi: 10.1016/j.semcdb.2016.01.010. PubMed PMID: 26805722.

88. Bhat R, Glimm T, Linde-Medina M, Cui C, Newman SA. Synchronization of Hes1 oscillations coordinates and refines condensation formation and patterning of the avian limb skeleton. Mech Dev. 2019;156:41-54. doi: 10.1016/j.mod.2019.03.001. PubMed PMID: 30867133.

89. Kageyama R, Shimojo H, Isomura A. Oscillatory Control of Notch Signaling in Development. Adv Exp Med Biol. 2018;1066:265-77. doi: 10.1007/978-3-31989512-3_13. PubMed PMID: 30030831.

90. Shimojo H, Ohtsuka T, Kageyama R. Oscillations in notch signaling regulate maintenance of neural progenitors. Neuron. 2008;58(1):52-64. doi:

10.1016/j.neuron.2008.02.014. PubMed PMID: 18400163. 